\title{
Occupational identity, job satisfaction and their effects on turnover intention among Chinese Paediatricians: a cross-sectional study
}

Wanjun Deng ${ }^{1 \dagger}$, Zhichun Feng ${ }^{2 \dagger}$, Xinying Yao ${ }^{1+}$, Tingting Yang ${ }^{3}$, Jun Jiang ${ }^{1}$, Bin Wang ${ }^{3}$, Lan Lin ${ }^{3}$, Wenhao Zhong ${ }^{1}$ and Oudong $\mathrm{Xia}^{3^{*}}$ (D)

\begin{abstract}
Background: This study contributes to research on the paediatrician shortage by examining occupational identity, job satisfaction and their effects on turnover intention among paediatricians in China.

Methods: A multi-stage stratified random sampling method was employed to conduct a questionnaire survey. Of the 4906 survey recipients, valid data were collected from 4198 of the respondents (85.6\%). The participants were from seven geographic regions of China (south, central, north, east, northwest, southwest, and northeast).

Paediatricians who volunteered and provided written informed consent participated. All variables including basic socio-demographics and work-related characteristics, occupational identity, job satisfaction and turnover intention were based on available literature, and measured on a 5- point Likert scale. Statistical methods such as exploratory factor analysis (EFA), descriptive analysis, common method bias, one-way ANOVA test, Pearson correlation analysis and mediation analysis were used.

Results: Significant differences were observed among the respondents in terms of turnover intention based on age, education level, marital status, region, the type and grade of practice setting, professional title, years in practise, workload, rest days, and monthly income. Occupational identity and job satisfaction were both negatively related to turnover intention, and occupational identity was positively correlated with job satisfaction $\left(r_{1}=-0.601, p<0.01\right.$; $\left.r_{2}=-0.605, p<0.01\right)$. The results also showed that job satisfaction played a mediating role in the association between occupational identity and turnover intention among Chinese paediatricians.

Conclusions: Work conditions, workload and salary are crucial factors of turnover intention among paediatricians in China. Therefore, we suggest that healthcare managers should increase investment in paediatrics, implement salary reforms and dedicate more attention to female and young paediatricians, thus reducing turnover intention among Chinese paediatricians.
\end{abstract}

Keywords: Paediatricians, Occupational identity, Job satisfaction, Turnover intention

\footnotetext{
*Correspondence: 791966640@qq.com

${ }^{\dagger}$ Wanjun Deng, Zhichun Feng and Xinying Yao contributed equally to this work.

${ }^{3}$ Zhujiang Hospital, Southern Medical University, Guangzhou 510280, China Full list of author information is available at the end of the article
}

(c) The Author(s). 2021 Open Access This article is licensed under a Creative Commons Attribution 4.0 International License, which permits use, sharing, adaptation, distribution and reproduction in any medium or format, as long as you give appropriate credit to the original author(s) and the source, provide a link to the Creative Commons licence, and indicate if changes were made. The images or other third party material in this article are included in the article's Creative Commons. licence, unless indicated otherwise in a credit line to the material. If material is not included in the article's Creative Commons licence and your intended use is not permitted by statutory regulation or exceeds the permitted use, you will need to obtain permission directly from the copyright holder. To view a copy of this licence, visit http://creativecommons.org/licenses/by/4.0/ The Creative Commons Public Domain Dedication waiver (http://creativecommons.org/publicdomain/zero/1.0/) applies to the data made available in this article, unless otherwise stated in a credit line to the data. 


\section{Background}

Since China's health system reform, its infant mortality has decreased from $50.2 \%$ in 1991 to $6.1 \%$ o in 2018; meanwhile, other child health indicators have improved considerably [1]. Despite steady improvement in paediatric services, China's child health system is in danger of collapse due to a shortage of paediatricians. As noted by the National Bureau of Statistics of China, the ratio of registered paediatricians aged less than 65 per 1000 children was 0.63 in 2017 [2]. Another survey addressing the characteristics and workload of paediatricians in China described that the distribution of paediatricians was extremely skewed (Gini coefficient 0.61 ), and that, in 2016, paediatricians were burdened with a greater workload [3]. At the same time, the universal two-child policy implemented on January 1, 2016, which aims to address the country's population aging trend, has exacerbated the shortage of paediatricians in China [4-7]. Moreover, paediatricians have one of the highest turnover rates among physician specialists [7]. According to the China Pediatric Resources White Paper, a total of 14,310 paediatricians, accounting for $10.7 \%$ of paediatricians in China, left their position for other professions between 2011 and 2014 [8]. The shortage of paediatricians and a high turnover rate have created challenges for China's paediatric health care system.

According to Erikson, occupational identity (OI) exists in early growth, adolescence and adulthood, and it can be strengthened and developed constantly throughout the lifespan [9]. Inspired by the formulations of Erikson, Holland conceptualized OI as a stable state with behaviours formed by individuals for their career goals, interests and abilities [10]. In contrast, Savickas proposed the self-concept of changing OI [11], and Vondracek described OI as a dynamic organization of career selfperception [12]. Hence, we assumed that OI refers to the development of self-consciousness and self-identity. Meeus discovered that the achievement and social support of adolescents in the educational environment promote the development of their OIs [13]. Early research explored OI among healthcare workers. Subsequently, in an investigation of the correlation between nurses' OI and environment, Leufgen also discovered that the environment has a positive effect on OI [14]. Wu [15] and Zhao [16] revealed that OI was associated with education, the type of practice setting and salary among healthcare workers in China. However, a study conducted by Selma et al. [17] demonstrated that OI was correlated with job satisfaction and an intention to leave the profession among nurses in Turkey. Meanwhile, Zhang et al. [18] confirmed that OI was a strong predictor of turnover intention (TI) among township health inspectors in China.
Job satisfaction has been a topic of research for decades. Hoppock proposed the concept of job satisfaction from psychological and physiological perspectives, and pointed out that job satisfaction refers to a subjective feeling that an employee holds towards his or her job [19]. Locke further recognized job satisfaction as a positive emotional state resulting from evaluations of one's work or work experience [20]. Job satisfaction is the extent to which people like (satisfaction) or dislike (dissatisfaction) their jobs [21], and refers to an attitude or emotional response to one's tasks as well as to the physical and social conditions of the workplace [22]. In fact, job satisfaction is related to many factors. Manojlovich [23] verified that factors in the practice environment contributed directly to nurses' job satisfaction. Healy et al. [24] and Ozyurt et al. [25] revealed that job satisfaction is inversely correlated with burnout. Jackson et al. [26] showed that women and young doctors may have a higher risk of dissatisfaction at work. In a study among Australian nurses' regarding job satisfaction and retention, Cowin and Leanne [27] also confirmed that experienced nurses had relatively stable job satisfaction, and that salary was a significant element of young nurses' job satisfaction. Additionally, job satisfaction is usually regarded as the most representative antecedent variable to predict the TI of health care providers. A previous study conducted by Porter and Sters [28] identified a significant negative correlation between job satisfaction and TI. Recently, a study among doctors in the district public-private mixed health system of Bangladesh also confirmed a significant negative correlation between job satisfaction and TI [29]. Tao et al. [30] demonstrated that job satisfaction was a strong predicator of TI among paediatricians in China. Furthermore, job satisfaction is often the mediator between other factors and turnover intention. Einar M. Skaalvik [31] explored the relationship between school environment variables and teachers' sense of belonging, and the results showed that job satisfaction was the intermediary variable between wages and job transfer intention. In accordance with this previous study, Chan SHJ verified [32] the mediating effect of job satisfaction on career adaptability and turnover intention. One result of the study that was consistent with the previous study was that job satisfaction has a negative impact on TI, and that the indirect effect is significant.

Turnover intention (TI), according to Mobley [33], is considered to be the best and intuitive predictor of actual turnover behavior, and it refers to the probability that an employee will voluntarily leave his or her job in the period ahead [34]. Some related research on TI has been undertaken extensively by scholars in various fields. As a study initiated by Mobley [33] pointed out, TI is a summative factor of other turnover-related factors and is 
significantly related to employee turnover. In another study, Shader [35] proposed that job and role stress are important factors leading to TI. Han et al. [36] indicated that factors such as job burnout, work pressure, workplace, working hours, self-efficacy are predictors of TI. Based on these studies, Scanlan, J. N [37] further explored the factors influencing occupational therapists' job well-being and TI; he discovered that all indicators of job happiness were significantly related to TI. As recognition has increased regarding the importance of the association between $\mathrm{TI}$ and the actual level of organization management [38], a large number of studies have focused on TI in occupational populations. A study among Jordanian nurses in psychiatric units by Alsaraireh et al. [39] found a significant negative correlation between job satisfaction and TI. Zhang et al. [18] demonstrated that professional identity, job satisfaction and work engagement were strong predicators of TI among township health inspectors in China.

Based on the above-mentioned theoretical analysis and empirical demonstrations, we attempted to link the relationship and moderating effect among OI, job satisfaction and TI. The model is presented in Table 1 and Fig. 1. We assumed that OI and job satisfaction directly affect TI. Meanwhile, through job satisfaction, OI has an indirect effect on TI. Thus, this study aimed to verify the direct impacts of OI and job satisfaction, and to explore and quantify the influencing mechanism of job satisfaction as an intermediate variable. In a stressful practice environment, paediatricians are subjected to higher workloads and work pressure and relatively low salaries, which may place pediatrician at risk for emotional exhaustion and increased levels of TI [40]. Related to this issue is the benign professional attitude construction of paediatricians. An increased understanding of the complex interrelationship between OI, job satisfaction and TI, and the mechanism of these three, can help to facilitate appropriate measures to counteract the issue of high turnover; this issue deserves more attention.

In recent years, the shortage of paediatricians in China has received extensive attention from all walks of life. On the one hand, the demand for pediatric medical care in China is increasing rapidly, on the other hand, the supply of pediatric medical resources is insufficient. However, what this issue essentially reveals is the bad

Table 1 The theoretical hypotheses

Hypotheses
1. Paediatricians' occupational identity has a direct negative effect on
turnover intention
2. Paediatricians' job satisfaction has a negative effect on turnover
intention
3. Paediatricians' occupational identity has an indirect negative effect on
turnover intention through the mediating effect of job satisfaction

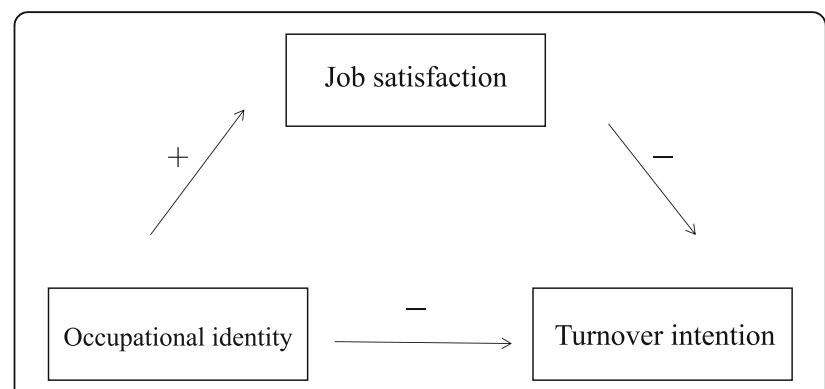

Fig. 1 The theoretical model and hypotheses

working condition of the Chinese paediatrician group, which in the study area is not studied before so this study will try to fill the information gap on the working condition of the Chinese paediatrician group. Also we administered a survey to registered paediatricians in China with the aims of identifying key factors that influence how paediatricians perceive their work, exploring the relations between OI, job satisfaction and TI, and developing new and better strategies to address the shortage of paediatricians.

\section{Methods}

\section{Setting and participants}

This study is part of the research project funded by the Humanities and Social Sciences of the Ministry of Education of China, "Exploration on Reasons and Countermeasures for the Shortage of paediatricians in China". Judging from the experience of sample size summarized by Yuan et al. [41], the sampling ratio is less than $1 \%$ when the overall scale is greater than 100,000 people. By the end of 2016, the number of paediatricians in China was 114,010 , according to national statistics; thus, the minimum sample size is 1141 (1\%). For the purpose of data reliability and validity, the estimated sample size for this survey is 4500. The research object for the influencing factors of TI was in-service paediatricians in medical institutions nationwide. Inclusion criteria: 1) A signed labour contract or other related labour agreement with a public medical institution; 2) Registered doctors with a license to practicing doctors; and 3) A position in relevant paediatrics departments of public medical institutions.

From August 2018 to December 2018, this study employed a multi-stage stratified random sampling method to conduct a questionnaire survey. First, according to China's geographical divisions, we divided the country into 7 regions of South China, Central China, North China, East China, Northwest China, Southwest China, and Northeast China, and according to the proportion of provinces in each region, we randomly 
selected 4 provinces in East China, 2 provinces each in South China, North China, Southwest China and Northwest China,and 1 province each in Central China and Northeast China. Second, we randomly selected 3 cities in all the provinces. Then, according to the proportions and grades of local medical institutions, we randomly selected 10 medical institutions and then randomly selected 10 to 12 paediatricians (including attending physicians and residents) from each institution.

Data were collected through self-administered questionnaires based on collaboration with the Pediatric Society of the Chinese Medical Doctor Association (PSCMDA) and the Neonatal Society of the Chinese Medical Doctor Association (NS-CMDA), which included four parts in addition to the cover letters. To reduce survey bias, this study adopted a self-administered questionnaire survey method. The cover letter informed the respondents that their information was confidential and used only for academic research. Every doctor who accepted the questionnaire survey voluntarily completed the questionnaire after providing informed consent and participated in the questionnaire survey. Secondly, the project team conducted standardized training for multiple investigators, including the research purpose, investigation content, investigation methods, and questionnaire distribution, recovery, and entry. Due to the long distance for some investigators, the training was conducted online. A total of 4906 questionnaires were distributed, and 4198 questionnaires were actually collected. The questionnaire recovery rate was $85.6 \%$.

\section{Study measures}

The study questionnaire, which contained 46 items, was based on an accepted international scale translated into Chinese. The predicted time to finish the questionnaire was $10-15 \mathrm{~min}$.

- Part 1 included basic socio-demographic and workrelated characteristics, including age, gender, education, marital status, region, the type and grade of practice setting, professional title, years in practice, the number of hospital beds, rest days in a week and monthly salary.

- In part 2, OI was measured using a 10-item Chinese version of the OI scale (CPIS) developed by Cai (2003) based on the original Occupational Identity Scale (Tyler \& McCallum, 1998) [42, 43]. Items included "My present job makes me feel very proud" and 9 other items. The CPIS has a 5-point response format, ranging from $1=$ "strongly disagree" to $5=$ "strongly agree". Total scores can range from 10 to 50 and higher scores indicate higher levels of OI.

- In part 3, job satisfaction was measured using the Chinese version of the Minnesota Satisfaction
Questionnaire-Short Version (MSQ-short version) developed by Wu based on the MSQ-short version developed by Weiss [44], a well-known and stable instrument used to measure job satisfaction. The MSQ-short version includes 20 items and two subscales: Intrinsic Job Satisfaction (IJS) (consisting of 12 items, including activity, independence, variety, social status, moral value, security, social service, authority, ability utilization, responsibility, creativity, achievement) and Extrinsic Job Satisfaction (EJS) (consisting of 6 items including supervision-human relation, supervision-technical, company policies and practices, salary, recognition). Two additional items explore satisfaction with working conditions and coworker relationships. The results are reported as General Job Satisfaction (GJS), which is the total score for all 20 items and subscale scores for intrinsic job satisfaction and extrinsic job satisfaction [45, 46]. The 20 items in the MSQ-short version are rated on a 5-point Likert scale (ranging from 1= "very dissatisfied with this aspect of my job" to $5=$ "very satisfied with this aspect of my job"). Item responses are summed or averaged to create a total score ranging from 20 to 100 , with a lower score corrseponding to a lower the level of job satisfaction [46].

- Part 4 consisted of a 4-item instrument measuring TI developed by Farh that is considered to have high internal uniformity and retest reliability $[47,48]$. The responses are based on a 5-point Likert scale (ranging from $1=$ "strongly disagree" to $5=$ "strongly agree"). Total scores can range from 4 to 20 and higher scores indicate higher levels of TI.

\section{Statistical analysis}

We analysed the collected data with SPSS 23.0 with the following methods and objectives: 1) Exploratory factor analysis (EFA) was used to scientifically assess the responsibility and validity of the whole questionnaire. 2) Descriptive analysis was performed to determine the numbers $(\mathrm{N})$ and percentages (\%) for socio-demographic and work-related characteristics as well as the means and standard deviations (SDs) for OI, job satisfaction, and TI. 3) The effects of an unmeasured latent method factor were controlled in a common method bias: three models were constructed with four items for OI (10 items), internal job satisfaction (12 items), external job satisfaction (6 items), and TI ( 4 items), and model differences were compared in AMOS 24.0; after adding the common method factor to the four-factor model, several indicators including the root mean square error of approximation (RMSEA) and standardized root mean square residual (SRMR) decreased or increased by no more than 0.05, while the comparative fit index (CFI) 
Table 2 Descriptive data for the socio-demographic and worked-related characteristics of paediatricians

\begin{tabular}{|c|c|c|c|c|c|}
\hline \multirow{3}{*}{ Characteristic } & \multirow{2}{*}{\multicolumn{2}{|c|}{ Total sample }} & \multirow{3}{*}{ Characteristic } & \multirow{2}{*}{\multicolumn{2}{|c|}{ Total sample }} \\
\hline & & & & & \\
\hline & $\mathrm{N}$ & $\%$ & & $\mathrm{~N}$ & $\%$ \\
\hline Age (years) & & & $6-10$ years & 868 & 20.7 \\
\hline $20-29$ & 594 & 14.1 & $11-15$ years & 606 & 14.4 \\
\hline $30-39$ & 1635 & 38.9 & 16-20 year & 459 & 10.9 \\
\hline $40-49$ & 1337 & 31.8 & $>20$ years & 1215 & 28.9 \\
\hline $50-59$ & 610 & 14.5 & Number of hospital beds & & \\
\hline$>=60$ & 22 & 0.05 & $<5$ & 379 & 9 \\
\hline Gender & & & $5-10$ & 1634 & 38.9 \\
\hline Male & 1256 & 29.9 & $11-15$ & 1243 & 29.6 \\
\hline Female & 2942 & 70.1 & $16-20$ & 409 & 9.7 \\
\hline Education & & & $>20$ & 533 & 12.7 \\
\hline College graduate & 223 & 5.3 & Rest day / week & & \\
\hline Bachelor's degree & 3035 & 72.3 & 0 day & 1568 & 37.4 \\
\hline Master's degree & 817 & 19.5 & 1 day & 1790 & 42.6 \\
\hline Doctorate degree & 123 & 2.9 & 2 days & 821 & 19.6 \\
\hline Marital & & & 3 days & 19 & 0.5 \\
\hline Not married (single and others) & 475 & 11.3 & Monthly income (CNY) & & \\
\hline Married & 3723 & 88.7 & $<10,000$ & 3462 & 82.5 \\
\hline Region & & & $10,001-20,000$ & 637 & 15.2 \\
\hline Northeast China & 534 & 12.7 & $20,001-30,000$ & 73 & 1.7 \\
\hline North China & 537 & 12.8 & $>30,000$ & 26 & 0.6 \\
\hline
\end{tabular}

South China

Central China

Northwest China

Southwest China

Type of practice setting

General hospital 2980

Children's hospital

Maternal and child care service centre

Other

Grade of practice setting

Primary

Secondary

Tertiary

Not rated

\section{Professional title}

Junior

Middle

Senior

Years in practice

$<1$ year

$1-5$ years
Table 2 Descriptive data for the socio-demographic and worked-related characteristics of paediatricians (Continued)

and Tucker-Lewis index (TLI) decreased or increased by no more than 0.1 , which reflecting an acceptable fit between the current data and the hypothesized model. 4) One-way analysis of variance was used to compare group differences in the socio-demographic variables. 5) Pearson correlation analysis was applied to OI, job satisfaction and TI. 6) The bootstrap method was used to analyse the mediating effect: internal job satisfaction and external job satisfaction were set as mediator variables(M), OI was set as the independent variable (X), and TI was set as the outcome variable $(\mathrm{Y})$. Then,model 6 and 5000 bootstrap samples were selected in SPSS PROCESS; the $\mathrm{X} \rightarrow \mathrm{Y}$ path regression equation and $\mathrm{X} /$ $\mathrm{M} \rightarrow \mathrm{Y}$ path regression equation must be significant, and the confidence interval for indirect effects did not include 0 , indicating that the effect of mediation was statistically significant.

Reliability and validity

In accordance with the EFA results, the Kaiser-MeyerOlkin (KMO) value of the CPIS was 0.924, and Bartlett's test of sphericity was significant $\left(\chi^{2}=21,661.103, P<\right.$ 0.01). The KMO of the MSQ was 0.941, and Bartlett's test of sphericity was significant $\left(\chi^{2}=35,957.862, P<\right.$ 0.01 ). The Kaiser-Meyer-Olkin (KMO) of TI was 0.784 
Table 3 Common method bias

\begin{tabular}{|c|c|c|c|c|c|c|}
\hline Model & $x^{2}$ & df & RMSEA & SRMR & TLI & CFI \\
\hline Single factor model & $19,055.63$ & 464 & 0.098 & 0.071 & 0.708 & 0.727 \\
\hline Four-factor model & $11,181.44$ & 458 & 0.075 & 0.057 & 0.829 & 0.842 \\
\hline Four-factor model + Common method factor & 8802.427 & 429 & 0.068 & 0.051 & 0.858 & 0.877 \\
\hline
\end{tabular}

and bartlett's test of sphericity was significant $\left(\chi^{2}=\right.$ 5533.583, $P<0.01$ ). All KMO values were greater than 0.70 , indicating a better possibility for factor analysis. Reliability analysis was performed and we found that Cronbach's $\alpha$ values for CPIS, MSQ and TI were 0.905 , 0.919 and 0.810 , respectively. A coefficient above 0.8 generally indicates acceptable reliability of a scale.

\section{Results}

\section{Descriptive analysis of the socio-demographic and} worked-related characteristics

A total of 4906 paediatricians were invited to participate in the study, and valid data were collected from 4198 of the respondents (85.6\%). Table 2 provides the descriptive statistics for the individual variables analysed in this study. The age of the respondents varied between 20 and 74 years, and approximately $85 \%$ of the respondents were younger than age 50 years of age. Most of the participants were female (70.1\%), and the most paediatricians in China are female. In terms of education, most of the respondents had a university degree or above (94.7\%), and most held a bachelor's degree. Most of the participants were married at the time of the study (88.7\%).

With respect to practice settings, most of the participants worked in a government general hospital (71\%), and smaller percentages worked in a children's hospital $(8.1 \%)$ or other settings $(1.7 \%)$. A considerable proportion of the respondents worked in a secondary (40.5\%) or tertiary (55.8\%) practice setting. Among the respondents, $29.3 \%$ were junior doctors, $30.6 \%$ were middle doctors, and $40.0 \%$ were senior doctors. More than half of the participants reported working for over 10 years (54.2\%). Most of the respondents reported being responsible for 5-15 hospital beds (68.5\%) and were most likely

Table 4 Descriptive data and ANOVA results for the socio-demographic characteristics of paediatricians

\begin{tabular}{|c|c|c|c|c|c|c|c|c|c|c|}
\hline \multirow[t]{2}{*}{ Characteristic } & \multicolumn{2}{|c|}{$\begin{array}{l}\text { Occupational } \\
\text { identity }\end{array}$} & \multicolumn{2}{|l|}{$\begin{array}{l}\text { General job } \\
\text { satisfaction }\end{array}$} & \multicolumn{2}{|l|}{$\begin{array}{l}\text { Intrinsic job } \\
\text { satisfaction }\end{array}$} & \multicolumn{2}{|l|}{$\begin{array}{l}\text { Extrinsic job } \\
\text { satisfaction }\end{array}$} & \multicolumn{2}{|l|}{$\begin{array}{l}\text { Turnover } \\
\text { intention }\end{array}$} \\
\hline & Mean (SD) & $P$ & Mean (SD) & $P$ & Mean (SD) & $P$ & Mean (SD) & $P$ & Mean (SD) & $P$ \\
\hline Age (years) & & ** & & $* *$ & & ** & & ** & & ** \\
\hline $20-29$ & $28.02(8.51)$ & & $61.64(13.25)$ & & $38.14(8.10)$ & & $17.03(4.61)$ & & $11.94(3.51)$ & \\
\hline $30-39$ & $26.81(8.13)$ & & $59.93(12.31)$ & & $37.42(7.69)$ & & $16.13(4.46)$ & & $11.82(3.21)$ & \\
\hline $40-49$ & $29.21(8.51)$ & & $61.14(11.60)$ & & $38.80(7.21)$ & & $15.98(4.38)$ & & $11.06(3.11)$ & \\
\hline $50-59$ & $31.82(8.31)$ & & $63.85(12.14)$ & & $40.23(7.64)$ & & $16.97(4.52)$ & & $10.20(3.30)$ & \\
\hline$>=60$ & $35.23(8.11)$ & & $64.91(8.18)$ & & $41.36(4.44)$ & & $17.00(3.51)$ & & $9.91(2.00)$ & \\
\hline Gender & & $* *$ & & $* *$ & & $* *$ & & $* *$ & & - \\
\hline Male & $27.61(8.82)$ & & $59.64(13.03)$ & & $37.31(8.25)$ & & $15.96(4.60)$ & & $11.48(3.27)$ & \\
\hline Female & $28.90(8.36)$ & & $61.80(11.85)$ & & $38.85(7.27)$ & & $16.50(4.42)$ & & $11.30(3.30)$ & \\
\hline Education & & $* *$ & & - & & - & & $* *$ & & * \\
\hline College graduate & $29.46(9.39)$ & & $61.89(12.13)$ & & $39.34(7.51)$ & & $16.08(4.54)$ & & $11.19(3.24)$ & \\
\hline Bachelor's degree & $28.15(8.48)$ & & $60.91(12.22)$ & & $38.28(7.60)$ & & $16.21(4.47)$ & & $11.44(3.31)$ & \\
\hline Master's degree & $29.20(8.14)$ & & $61.59(12.11)$ & & $38.41(7.49)$ & & $16.74(4.38)$ & & $11.15(3.22)$ & \\
\hline Doctorate degree & $31.41(9.37)$ & & $62.94(14.09)$ & & $39.29(8.67)$ & & $17.10(5.14)$ & & $10.71(3.33)$ & \\
\hline Marital & & - & & - & & - & & $* *$ & & ** \\
\hline Not married (single and other) & $28.28(8.30)$ & & $61.85(12.79)$ & & $38.14(7.86)$ & & $17.23(4.40)$ & & $11.83(3.47)$ & \\
\hline Married & $28.55(8.54)$ & & $61.06(12.18)$ & & $38.42(7.58)$ & & $16.22(4.48)$ & & $11.29(3.26)$ & \\
\hline Total & $28.52(8.52)$ & & 61.15 (12.25) & & $38.39(7.61)$ & & $16.34(4.48)$ & & 11.35 (3.29) & \\
\hline
\end{tabular}

Note: ${ }^{*} p<0.05,{ }^{* *} p<0.01$ 
Table 5 Descriptive data and ANOVA results for the work-related characteristics of paediatricians

\begin{tabular}{|c|c|c|c|c|c|c|c|c|c|c|}
\hline \multirow[t]{2}{*}{ Characteristic } & \multicolumn{2}{|c|}{$\begin{array}{l}\text { Occupational } \\
\text { identity }\end{array}$} & \multicolumn{2}{|l|}{$\begin{array}{l}\text { General job } \\
\text { satisfaction }\end{array}$} & \multicolumn{2}{|l|}{$\begin{array}{l}\text { Intrinsic job } \\
\text { satisfaction }\end{array}$} & \multicolumn{2}{|l|}{$\begin{array}{l}\text { Extrinsic job } \\
\text { satisfaction }\end{array}$} & \multicolumn{2}{|l|}{$\begin{array}{l}\text { Turnover } \\
\text { intention }\end{array}$} \\
\hline & Mean (SD) & $P$ & Mean (SD) & $P$ & Mean (SD) & $P$ & Mean (SD) & $P$ & Mean (SD) & $P$ \\
\hline Region & & ** & & $* *$ & & $* *$ & & ** & & ** \\
\hline Northeast China & $27.62(7.68)$ & & $61.19(11.72)$ & & $38.52(7.35)$ & & $16.40(4.34)$ & & $11.73(3.11)$ & \\
\hline North China & $29.97(8.74)$ & & $62.12(13.31)$ & & $38.93(8.13)$ & & $16.68(4.79)$ & & $10.95(3.38)$ & \\
\hline East China & $29.21(8.26)$ & & $61.14(12.39)$ & & $38.39(7.57)$ & & $16.15(4.49)$ & & $10.92(3.17)$ & \\
\hline South China & $28.33(8.47)$ & & $61.77(11.67)$ & & $38.49(7.43)$ & & $16.79(4.18)$ & & $11.36(3.23)$ & \\
\hline Central China & $27.95(8.52)$ & & $60.60(11.58)$ & & $38.08(7.39)$ & & $16.07(4.27)$ & & $11.58(3.09)$ & \\
\hline Northwest China & $27.60(8.74)$ & & $59.03(12.25)$ & & $37.46(7.53)$ & & $15.35(4.55)$ & & $11.64(3.25)$ & \\
\hline Southwest China & $29.03(8.87)$ & & $62.39(12.60)$ & & $38.96(7.79)$ & & $16.98(4.56)$ & & $11.29(3.68)$ & \\
\hline Type of practice setting & & $* *$ & & - & & - & & $* *$ & & ** \\
\hline General hospital & $28.22(8.50)$ & & $60.87(12.15)$ & & $38.25(7.56)$ & & $16.19(4.42)$ & & $11.44(3.30)$ & \\
\hline Children's hospital & $29.47(8.60)$ & & $62.55(12.39)$ & & $38.93(7.46)$ & & $17.21(4.66)$ & & $10.70(3.34)$ & \\
\hline Maternal and child care service centre & $29.00(8.46)$ & & $61.50(12.68)$ & & $38.56(7.87)$ & & $16.47(4.64)$ & & $11.28(3.22)$ & \\
\hline Other & $30.73(8.62)$ & & $62.43(10.49)$ & & $39.71(7.11)$ & & $16.57(3.62)$ & & $11.56(3.21)$ & \\
\hline Grade of practice setting & & $* *$ & & $* *$ & & $* *$ & & $* *$ & & ** \\
\hline Primary & $28.31(8.95)$ & & $59.46(11.39)$ & & $37.54(7.45)$ & & $15.77(3.99)$ & & $11.49(3.37)$ & \\
\hline Secondary & $27.73(8.49)$ & & $60.01(12.26)$ & & $37.93(7.73)$ & & $15.74(4.47)$ & & $11.69(3.25)$ & \\
\hline Tertiary & $29.08(8.45)$ & & $62.04(12.14)$ & & $38.73(7.46)$ & & $16.79(4.45)$ & & $11.10(3.29)$ & \\
\hline Not rated & $29.39(9.84)$ & & $61.89(14.90)$ & & $39.36(9.63)$ & & $16.23(4.82)$ & & $11.41(3.39)$ & \\
\hline Professional title & & $* *$ & & $* *$ & & $* *$ & & $* *$ & & ** \\
\hline Junior & $27.70(8.62)$ & & $61.20(13.04)$ & & $37.89(8.00)$ & & $16.85(4.60)$ & & $11.81(3.44)$ & \\
\hline Middle & $26.81(8.11)$ & & $59.02(11.70)$ & & $37.25(7.37)$ & & $15.47(4.32)$ & & $11.77(3.12)$ & \\
\hline Senior & $30.42(8.38)$ & & $62.75(11.83)$ & & $39.62(7.32)$ & & $16.62(4.42)$ & & $10.70(3.20)$ & \\
\hline Years in practice & & $* *$ & & $* *$ & & ** & & $* *$ & & $* *$ \\
\hline$<1$ year & $31.13(8.36)$ & & $64.91(13.47)$ & & $39.58(8.08)$ & & $18.43(4.75)$ & & $10.92(3.45)$ & \\
\hline $1-5$ years & $27.88(8.54)$ & & $61.12(12.88)$ & & $37.91(7.90)$ & & $16.83(4.54)$ & & $11.68(3.44)$ & \\
\hline $6-10$ years & $26.69(8.01)$ & & $59.93(12.21)$ & & $37.57(7.64)$ & & $15.95(4.42)$ & & $12.00(3.13)$ & \\
\hline $11-15$ years & $27.20(8.58)$ & & $60.25(12.00)$ & & $37.90(7.45)$ & & $15.99(4.38)$ & & $11.61(3.20)$ & \\
\hline 16-20 year & $28.23(8.36)$ & & $59.92(11.83)$ & & $37.86(7.47)$ & & $15.66(4.42)$ & & $11.24(3.18)$ & \\
\hline$>20$ years & $30.72(8.37)$ & & $62.49(11.71)$ & & $39.61(7.28)$ & & $16.41(4.41)$ & & $10.61(3.21)$ & \\
\hline Number of hospital beds & & $* *$ & & $* *$ & & $* *$ & & $* *$ & & $* *$ \\
\hline$<5$ & $30.03(8.51)$ & & $63.02(13.08)$ & & $39.36(7.90)$ & & $17.16(4.77)$ & & $10.63(3.36)$ & \\
\hline $5-10$ & $28.38(8.15)$ & & $61.46(11.87)$ & & $38.62(7.30)$ & & $16.39(4.38)$ & & $11.45(3.16)$ & \\
\hline $11-15$ & $27.75(8.42)$ & & $60.36(11.78)$ & & $37.82(7.37)$ & & $16.15(4.38)$ & & $11.58(3.28)$ & \\
\hline $16-20$ & $27.90(8.70)$ & & $59.64(12.74)$ & & $37.46(8.13)$ & & $15.85(4.44)$ & & $11.40(3.35)$ & \\
\hline$>20$ & $30.14(9.34)$ & & $61.89(13.24)$ & & $39.04(8.26)$ & & $16.39(4.76)$ & & $11.00(3.49)$ & \\
\hline Rest days / week & & $* *$ & & $* *$ & & $* *$ & & $* *$ & & $* *$ \\
\hline 0 day & $26.29(8.43)$ & & $58.15(12.29)$ & & $36.54(7.74)$ & & $15.41(4.41)$ & & $12.16(3.22)$ & \\
\hline 1 day & $29.32(8.38)$ & & $62.27(12.02)$ & & $39.12(7.43)$ & & $16.63(4.45)$ & & $11.01(3.20)$ & \\
\hline 2 days & $30.90(7.98)$ & & $64.32(11.43)$ & & $40.25(6.98)$ & & $17.41(4.35)$ & & $10.55(3.28)$ & \\
\hline 3 days & $34.53(6.35)$ & & $66.89(12.17)$ & & $41.68(7.08)$ & & $18.11(4.78)$ & & $10.89(3.41)$ & \\
\hline Monthly income (CNY) & & $* *$ & & $* *$ & & $* *$ & & $* *$ & & $* *$ \\
\hline$<10,000$ & $27.86(8.46)$ & & $60.42(12.22)$ & & $37.96(7.60)$ & & $16.08(4.47)$ & & $11.61(3.24)$ & \\
\hline
\end{tabular}


Table 5 Descriptive data and ANOVA results for the work-related characteristics of paediatricians (Continued)

\begin{tabular}{|c|c|c|c|c|c|c|c|c|c|c|}
\hline \multirow[t]{2}{*}{ Characteristic } & \multicolumn{2}{|c|}{$\begin{array}{l}\text { Occupational } \\
\text { identity }\end{array}$} & \multicolumn{2}{|l|}{$\begin{array}{l}\text { General job } \\
\text { satisfaction }\end{array}$} & \multicolumn{2}{|l|}{$\begin{array}{l}\text { Intrinsic job } \\
\text { satisfaction }\end{array}$} & \multicolumn{2}{|c|}{$\begin{array}{l}\text { Extrinsic job } \\
\text { satisfaction }\end{array}$} & \multicolumn{2}{|l|}{$\begin{array}{l}\text { Turnover } \\
\text { intention }\end{array}$} \\
\hline & Mean (SD) & $P$ & Mean (SD) & $P$ & Mean (SD) & $P$ & Mean (SD) & $P$ & Mean (SD) & $P$ \\
\hline $10,001-20,000$ & $31.19(8.02)$ & & 63.95 (11.68) & & $40.01(7.19)$ & & $17.31(4.25)$ & & $10.21(3.19)$ & \\
\hline $20,001-30,000$ & $33.03(8.05)$ & & 68.34 (10.74) & & $42.42(6.35)$ & & $19.07(4.22)$ & & 9.19 (3.32) & \\
\hline$>30,000$ & $37.46(8.12)$ & & $70.77(14.87)$ & & $44.42(9.94)$ & & $19.19(5.36)$ & & $10.54(4.07)$ & \\
\hline
\end{tabular}

Note: ${ }^{*} p<0.05,{ }^{* *} p<0.01$

to have 1 day of rest each week (42.6\%).A monthly salary $<10,000$ yuan was reported by $82.5 \%$ of the respondents.

\section{Common method bias analysis of occupational identity, job satisfaction and turnover intention}

We controlled for the effects of an unmeasured latent method factor to verify whether a common method bias existed. The single-factor model had a poor fit, and the four-factor model had a good fit (Table 3). After adding the common method factor to the four-factor model, the fitting index of model was not substantially improved. The RMSEA and SRMR reductions were not more than 0.05 (Table 3), and the CFI and TLI increases were not greater than 0.1 (Table 3), indicating that the fit of the model with the method factor did not result in significant improvement, and that although a common method bias may exist, it had little impact on the study [49].

The status quo of occupational identity, job satisfaction and turnover intention among Paediatricians

The mean score for OI was 28.52, with scores ranging from 10 to $50(\mathrm{SD}=8.516)$ (Table 4$)$. The ANOVA revealed that with the exception of marital status, all the socio-demographic and work-related characteristics were significantly associated with OI (Tables 4 and 5).

In the terms of job satisfaction, the distribution of the paediatricians' responses to the 20 5-point indicators within the 4 dimensions is shown in Tables 4 and 5 . The mean total score for general job satisfaction was 61.15, with scores ranging from 20 to $100(\mathrm{SD}=12.252$ ) (Table $4)$. In addition, the mean score for intrinsic job satisfaction was 38.39 (ranged from 12 to 60), while the mean score for extrinsic job satisfaction was 16.34 (ranged from 6 to 30). The results of the ANOVAs revealed that age, gender, region, the grade of practice setting, professional title, years in practice, workload, rest days, and monthly income were significantly associated with general job satisfaction (Tables 4 and 5).

The mean total score for TI was 11.35 , with scores ranging from 4 to $20(\mathrm{SD}=3.289)$ (Table 4$)$. The research results also showed that there were significant differences among the respondents in terms of TI based on age, education, marital status, region, the type and grade of practice setting, professional title, years in practise, workload, rest days, and monthly income (Tables 4 and 5).

\section{Pearson correlation analysis of occupational identity, job} satisfaction and turnover intention

Correlation analysis was conducted on the OI, job satisfaction and TI among Chinese paediatricians (Table 6). The study validated that the level of OI was positively correlated with the respondents' scores for general job satisfaction as well as intrinsic job satisfaction and extrinsic job satisfaction $\left(\mathrm{r}_{1}=0.702, p<0.01 ; \mathrm{r}_{2}=0.704\right.$, $p<0.01 ; \mathrm{r}_{3}=0.564, p<0.01$, respectively). The study validated that the level of TI was negatively correlated with the respondents' scores for OI, general job satisfaction, intrinsic job satisfaction and extrinsic job satisfaction $\left(\mathrm{r}_{1}=-0.601, p<0.01 ; \mathrm{r}_{2}=-0.605, p<0.01 ; \mathrm{r}_{3}=-0.563\right.$, $p<0.01 ; \mathrm{r}_{4}=-0.557, p<0.01$, respectively).

\section{Mediating effect analysis of occupational identity, job satisfaction and turnover intention}

We used the bootstrap method to analyse the mediating effect, which showed that intrinsic job satisfaction and

Table 6 Pearson bivariate correlations

\begin{tabular}{|c|c|c|c|c|c|c|}
\hline Item & Mean & SD & 1 & 2 & 3 & 4 \\
\hline 1) Occupational identity & 28.52 & 8.516 & NA & & & \\
\hline 2) General job satisfaction & 61.15 & 12.252 & $.702^{* *}$ & NA & & \\
\hline 3) Intrinsic job satisfaction & 38.39 & 7.607 & $.704^{* *}$ & $.953^{* *}$ & NA & \\
\hline 4) Extrinsic job satisfaction & 16.34 & 4.481 & $.564^{* *}$ & $.878^{* *}$ & $.706^{* *}$ & NA \\
\hline 5) Turnover intention & 11.35 & 3.289 & $-.601^{* *}$ & $-.605^{* *}$ & $-.563^{* *}$ & $-.557^{* *}$ \\
\hline
\end{tabular}

Note: ${ }^{*}$ Correlation is significant at the $P<0.05$ level, ${ }^{*}$ Correlation is significant at the $P<0.01$ level 
extrinsic job satisfaction mediate relationships between $\mathrm{OI}$ and TI. The direct effect refers to $\mathrm{X} \rightarrow \mathrm{Y}$ path regression, and the indirect effect refers to $\mathrm{X} / \mathrm{M} \rightarrow \mathrm{Y}$ path regression. The total effect is the sum of the direct effect and the indirect effect, and the relative mediating effect is the proportion of the indirect effect in the total effect. Thus, the total indirect effect was 0.09 , and the total effect was 0.223 . We also found that OI to EJS was 0.070 and IJS to TI was -0.045 . They were far less than OI to IJS (0.621), IJS to EJS (0.359) and EJS to TI(- 0.209). So we used a serial mediation model to explain the mediating effect of OI, IJS, EJS and TI. To some extent, the mediating effect of OI to TI through IJS and then EJS were far more than themselves. The mediating effect analysis revealed that OI generates TI through four paths: First, OI directly affects $\mathrm{TI}(\mathrm{X} \rightarrow \mathrm{Y})$, and the direct effect was $-0.133(-0.145,-0.120)$ (Fig. 2). Second, OI indirectly affects TI through intrinsic job satisfaction $(\mathrm{X} \rightarrow \mathrm{M} 1 \rightarrow$ $\mathrm{Y})$. The indirect effect was $-0.028(-0.039,-0.017)$, and the ratio in the mediating effect was $12.56 \%$ (Table 7 ). Third, OI indirectly affects TI through extrinsic job satisfaction $(\mathrm{X} \rightarrow \mathrm{M} 2 \rightarrow \mathrm{Y})$. The indirect effect was $0.015(-0.019,-0.011)$ and the ratio in the mediating effect was $6.73 \%$ (Table 7). Fourth, OI indirectly affects TI through intrinsic job satisfaction and extrinsic job satisfaction $(\mathrm{X} \rightarrow \mathrm{M} 1 \rightarrow \mathrm{M} 2 \rightarrow \mathrm{Y})$. The indirect effect was $0.047(-0.053,-0.040)$, and the ratio in the mediating effect was $21.08 \%$ (Table 7 ).

\section{Discussion}

The study explored the effects of OI, job satisfaction and TI among paediatricians in China. Our findings demonstrate that OI, job satisfaction, and TI are prevalent among Chinese paediatricians. Furthermore, we show that paediatricians with increased job satisfaction and OI were significantly less likely to have a strong TI.

Of the 12 intrinsic job satisfaction items, workload received the lowest score. According to data provided by the PS-CMDA, in Beijing Children's Hospital, each paediatrician should offer 80 to 100 visits each day and sometimes up to 150 visits per day. Similar conditions

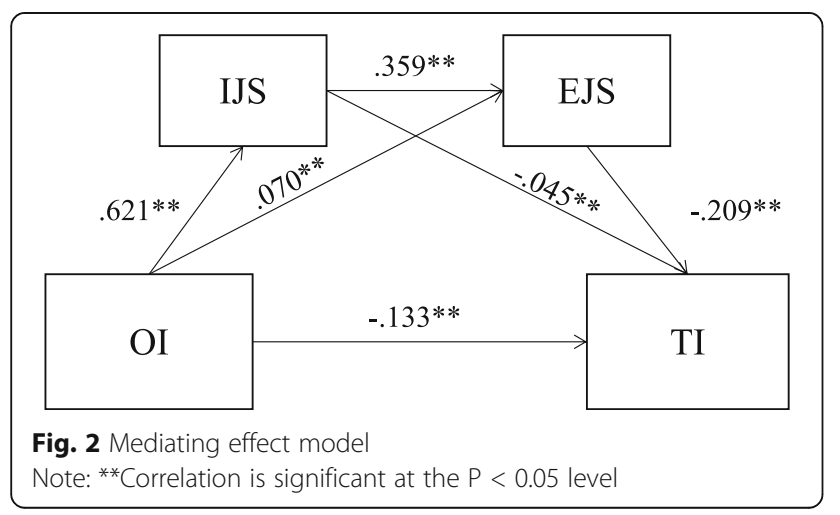

have also been observed in other paediatric medical centres [50]. Additionally, the number of hospital beds and rest days are two of the major factors affecting paediatricians' TI. On the whole, compared to the participants responsible for $\leqq 10$ hospital beds, paediatricians responsible for $>10$ hospital beds had lower OI and job satisfaction results and higher TIs. According to Wang (2010), the standard number of hospital beds for which paeditricians are responsible in tertiary general hospitals is 9.11 [51]. In our study, $52.0 \%$ of the paediatricians were responsible for $>10$ hospital beds, and more than half of the participants were responsible for more hospital beds than the number recommended in related reference criteria. In addition, regarding the rest days, $80.0 \%$ of the participants took 0 or only 1 rest day per week (Table 2 ). On the one hand, with the implementation of the two-child policy, the scope of the new baby boom has increased demands for children's health services and necessitated more talented practitioners in paediatrics. On the other hand, paediatrics departments are subjected to the phenomenon of turnover among paediatricians. The departure of paediatricians with rich experience, especially young paediatricians, is detrimental for medical institutions. According to the China Pediatric Resources White Paper, from 2011 to 2014, the loss rate of paediatricians under 35 -years of age was $14.6 \%$, the loss rate of those aged 35 -to- 45 -years was $11 \%$, and the loss rate of those aged 45-to-60-years was 6.8\% [8]. Therefore, the heavy workload is a product of the shortage of talent and the increasing demand for services.

With a limited paediatric workforce and increasing demands for child health care, paediatricians are facing unprecedented challenges. Of the 6 extrinsic job satisfaction items, salary received the lowest score. At the same time, salary is one of the significant direct and indirect predictors of TI. Salary has been identified as a contributing factor to a high level of TI [52-54]. A survey performed by the PS-CMDA found that approximately $96 \%$ of paediatricians were not satisfied with their salaries in 2011 [50]. The average salary of China's urban employees in the financial sector reached $122,851 \mathrm{CNY}$ in 2017, according to national data, and that of urban employees in the computer services and software industry was $133,150 \mathrm{CNY}$; by comparison, the salary of paediatricians lagged behind those of the two other industries [55]. On the one hand, the low salary of physicians is strictly controlled by the government to maintain affordable health care [56]. According to a survey conducted by the PS-CMDA, in 2015, the workload of paediatricians in general hospitals was 1.68-times that of nonpaediatricians, while the income earned by paediatricians was $46 \%$ of the income earned by non-paediatricians [57]. Compared to other physicians, because of the limited revenue generated by paediatric departments, an 
Table 7 Mediating effects analysis of occupational identity on turnover intention

\begin{tabular}{llllll}
\hline $\begin{array}{l}\text { Mediation } \\
\text { variable }\end{array}$ & $\begin{array}{l}\text { Indirect } \\
\text { effect }\end{array}$ & $\begin{array}{l}\text { Boot } \\
\text { SE }\end{array}$ & Boot Cl & Lower bound & Upper bound \\
\hline IJS & -.028 & .006 & -.039 & -.017 & $\begin{array}{l}\text { Relative } \\
\text { mediating } \\
\text { effect/\% }\end{array}$ \\
EJS & -.015 & .002 & -.019 & -.011 & 12.56 \\
IJS EJS & -.047 & .003 & -.053 & -.040 & 21.08 \\
\hline
\end{tabular}

income gap exists, increasing the likelihood of paediatricians experiencing fatigue and frustration.

Through Pearson correlation analysis, we observed active correlations between OI, intrinsic job satisfaction and extrinsic job satisfaction, which have negative correlations with TI. These findings are consistent with the negative correlation identified between OI and TI among Chinese nurses $[30,58]$, and a study exploring job satisfaction and TI among paediatricians reported the negative impacts of age and job satisfaction on TI [30]. Moreover, the mediating effect analysis revealed that in addition to directly affecting TI, OI also affects internal job satisfaction and then external job satisfaction; the highest indirect effect was $21.08 \%$, indicating tha OI generates TI through internal job satisfaction (12.56\%), rather than extrinsic job satisfaction (6.73\%), and that internal job satisfaction also affects external job satisfaction. Although internal job satisfaction and external job satisfaction function in the same direction, they have inconsistent roles; thus, other variables must affect the effects of the two, suggesting that future research should also fully explore the impacts of the latent variables internal job satisfaction and external job satisfaction.

\section{Strengths and limitations of this study}

To our knowledge, this is the first study to investigate OI, job satisfaction and TI at a national level and to analyse relationships between OI, job satisfaction and TI among paediatricians in China. We invested extensive time and energy in investigating many paediatricians to achieve a representative sample by planning a reasonable method for sample selection in China.

There are several limitations to our study. This is only a cross-sectional study, and no causal inferences can be made. In addition, because the questionnaire involves personal privacy, some respondents may have concealed their real experiences, resulting in a potential reporting bias in the study. Third, the study focused only on the relationships between OI, job satisfaction and TI among paediatricians. The study was conducted from a unilateral view, and some factors may have been ignored. Therefore, we should expand the field of investigation and identify additional problems in future research. On the basis of the research, in-depth interviews with stakeholder groups can be conducted to introduce new variables of research value to explore influencing factors.
Through a follow-up survey of paediatricians and cohort research, we can understand the true status and needs of paediatricians while conducting corresponding empirical research on the salaries of paediatricians and the promotion of professional titles.

\section{Conclusions}

Paediatricians play a vital role in the paediatric health system in China. The results show that higher OI and job satisfaction contribute to a decreased TI, providing not only new ideas for explaining the resignation of paediatricians, but also new possible and feasible methods to reduce the tendency towards resignation. Based on the results, we suggest that healthcare managers should improve vacation polices, increase financial investments in paediatric departments, fund projects including paediatric infrastructure, scientific research, and education by providing grant allowances to paediatricians, and most importantly, reform salaries for paediatricians. In addition, the government should focus on the rights of young paediatricians, as they represent a large percentage of Chinese paediatricians but have a high level of TI, provide them with more talent selection and advanced learning opportunities, and strengthen their psychological well-being.

\section{Abbreviations}

OI: Occupational identity; JS: Job satisfaction; Tl: Turnover intention;

GJS: General job satisfaction; IJS: Intrinsic job satisfaction; EJS: Extrinsic job satisfaction; PS-CMDA: The Pediatric Society of the Chinese Medical Doctor Association; NS-CMDA: The Neonatal Society of the Chinese Medical Doctor Association

\section{Acknowledgements}

We would like to thank the Pediatric Society of the Chinese Medical Doctor Association, the Neonatal Society of the Chinese Medical Doctor Association and all the participants for their cooperation.

Consent for publication

Not applicable.

\section{Authors' contributions}

DWJ, FZC, XOD and WB carried out the investigation work and the data collection and interpretation. DWJ, FZC, XOD, YTT and LL participated in the design and coordination of the investigation work and collected data. DWJ, $Y X Y, J J$ and ZWH participated in the study design, data collection, analysis of the data and preparation of the manuscript. YXY, LL and XOD carried out the study design and the analysis and interpretation of the data and drafted the manuscript. All authors read and approved the final manuscript.

\section{Funding}

The project was funded by the Humanities and Social Sciences of the Ministry of Education of China (17YJAZH093). The funding body had 
representation on providing financial assistance and project review, but played no role in the design of this study and during its execution,analyses,interpretation of the data,or decision to submit results. The authors' analysis and interpretation of the evidence are their own .

\section{Availability of data and materials}

All authors confirm that the data in this study will be made available from the corresponding author upon reasonable request.

\section{Ethics approval and consent to participate}

Ethical clearance was obtained from the ethics committee of Zhujiang Hospital of the Southern Medical University (2018-JWC-001). Signed informed consent was obtained from each participant. Confidentiality and anonymity were assured and confirmed. Participants were informed of their rights to withdraw from the study. All data have been secured safely with limited access to the authors only.

\section{Competing interests}

The authors declare that they have no competing financial interests.

\section{Author details}

${ }^{1}$ School of Health Management, Southern Medical University, Guangzhou 510515, China. 'BaYi Children's Hospital, The Seventh Medical Center of PLA General Hospital, Beijing 100000, China. ${ }^{3}$ Zhujiang Hospital, Southern Medical University, Guangzhou 510280, China.

\section{Received: 5 January 2020 Accepted: 2 December 2020}

Published online: 04 January 2021

\section{References}

1. National Health Commisson of the People's Repulic of China. China women and children health care development report. Beijing: Press Conference on China Women and Children Health Care Development Report; 2019.

2. National Health Commisson of the People's Repulic of China. China health statistical yearbook: People's Medical Publishing House (China); 2018.

3. Zhang YJ, Huang LS, Zhou X, et al. Characteristics and workload of paediatricians in China. Pediatrics. 2019;144:1.

4. Song QX, Wang F, Song L, Zhuang N, et al. The paediatrician demands and gaps under the universal two-child policy. Chinese J Health Policy. 2016;9:65-70.

5. Zhao YR. Analysis of the current situation of pediatric resource allocation and service based on the implementation of the two-child policy. China Health Ind. 2017;26:163-5.

6. Feng W. Analysis on healthcare service for children in China. Chin Hosp. 2012;16:19-21.

7. LV JX, Xu TC, Andrew Y, et al. Prediction and analysis of the number of paediatricians under policy adjustment. Chinese J Health Policy. 2017:10:34-40.

8. Chinese Pediatric Society of Chinese Medical Association, Pediatric Society of the Chinese Medical Doctor Association. China Pediatric Resources White Paper. Xiameng, China: The 10th Annual Meeting of Chinese Hospital Presidents 2016.

9. Erikson EH. Identity: youth and crisis (No. 7). New York: WW Norton \& Company; 1968. https://doi.org/10.1016/s0033-3182(68)71853-3.

10. Holland $J \mathrm{~L}$, Johnston JA, Asama NF. The vocational identity scale: a diagnostic and treatment tool. J Career Assess. 1993;1(1):1-12. https://doi. org/10.1177/106907279300100102.

11. Savickas ML, et al. Life designing: a paradigm for career construction in the 21st century. J Vocat Behav. 2009;75(3):239-50. https://doi.org/10.1016/j.jvb. 2009.04.004

12. Skorikov, Vladimir B, Fred WV. "Occupational identity". Handbook of identity theory and research. New York: Springer; 2011. p. 693-714. https://doi.org/ 10.1007/978-1-4419-7988-9.

13. Meeus W. Occupational identity development, school performance, and social support in adolescence: findings of a Dutch study. Adolescence. 1993; 28(112):809-19.

14. Leufgen M. Finding a personal role. Occupational identity in the tense relationship between nurses and the environment. Pflege Zeitschrift. 2010; 63(12):750-3.

15. Wu H. Public hospital medical workers' professional identity research. M.D. Thesis, Southwestern University of Finance and Economics, Chengdu, China. 2012.
16. Zhao Q. A study on physicians' professional identity and its influential factors in 36 public teriary hospitals in China. M.D. Thesis, Peking Union Medical College, Peking, China. 2017.

17. Sabanciogullari S, Dogan S. Relationship between job satisfaction, professional identity and intention to leave the profession among nurses in Turkey. J Nurs Manag. 2015;23:1076-85. https://doi.org/10.1111/jonm.12256.

18. Zhang WJ, Meng HD, Yang SJ, et al. The influence of professional identity, job satisfaction, and work engagement on turnover intention among township health inspectors in China. Int J Environ Res Public Health. 2018; 15:988. https://doi.org/10.3390/ijerph15050988.

19. Hoppock R. Job satisfaction; 1935.

20. Locke, E. A. What is job satisfaction? Organizational behavior and human performance. Motivation in Work Organizations, 1973.https://doi.org/10. 1016/0030-5073(69)90013-0.

21. Spector PE. Job satisfaction: application, assessment, causes and consequences. Thousand Oaks: Sage Publications; 1997. https://doi.org/10. 4135/9781452231549.

22. Sattar A, Khan S, Nawaz A. Theories of job-satisfaction: global applications \& limitations. Gomal Univ J Res. 2010;26:45-62.

23. Manojlovich M. Linking the practice environment to nurses' job satisfaction through nurse-physician communication. J Nurs Sch. 2005;37:367-73. https://doi.org/10.1111/j.1547-5069.2005.00063.x.

24. Healy CM, MCKay MF. Nursing stress: the effects of coping strategies and job satisfaction in a sample of Australian nurses. J Adv Nurs. 2000;31:681-8. https://doi.org/10.1046/j.1365-2648.2000.01323.x.

25. Ozyurt A, Hayran O, Sur H. Predictors of burnout and job satisfaction among Turkish physicians. QJM-AN Int J Med. 2006;99:161-9. https://doi.org/10. 1093/qjmed/hcl019.

26. Jackson TN, et al. The physician attrition crisis: a cross-sectional survey of the risk factors for reduced job satisfaction among US surgeons. World J Surg. 2018;42:1285-92. https://doi.org/10.1007/s00268-017-4286-y.

27. Cowin L. The effects of nurses' job satisfaction on retention: an Australian perspective. J Nurs Adm. 2002;32:283-91. https://doi.org/10.1097/00005110200205000-00008

28. Porter LW, Steers RM, Mowday RT, Boulian PV. Organizational commitment, job satisfaction, and turnover among psychiatric technicians. J Appl Psychol. 1974;59(5):603. https://doi.org/10.1037/h0037335.

29. Roy A, van der Weijden T, de Vries N. Relationships of work characteristics to job satisfaction, turnover intention, and burnout among doctors in the district public-private mixed health system of Bangladesh. BMC Health Serv Res. 2017;17(1):421. https://doi.org/10. 1186/s12913-017-2369-y.

30. Tao JX, Rui QQ, Yu CY, et al. Investigation on job satisfaction and turnover intention of paediatricians in Zhejiang Province. Chinese Hosp Manage. 2015;35:50-2 10.01-5329(2015)07-0050-03.

31. Skaalvik EM, Skaalvik S. Satisfaction and motivation to leave the teaching profession: Relations with school context, feeling of belonging, and emotional exhaustion. Teach Teach Educ. 2011;27(6):1029-38. https://doi. org/10.1016/j.tate.2011.04.001.

32. Chan SHJ, Mai X. The relation of career adaptability to satisfaction and turnover intentions. J Vocat Behav. 2015;89:130-9. https://doi.org/10.1016/j. jvb.2015.05.005

33. Mobley $\mathrm{WH}$. Intermediate linkages in the relationship between job satisfaction and employee turnover. J Appl Psychol. 1977;62(2):237-40. https://doi.org/10.1037/0021-9010.62.2.237.

34. March JG, Simon HA. Organizations. Rochester: Social Science Electronic Publishing; 1958. p. 105-32. https://doi.org/10.2307/2390654.

35. Shader K, Broome ME, Broome CD, West ME, Nash M. Factors influencing satisfaction and anticipated turnover for nurses in an academic medical center. J Nurs Adm. 2001;31:210-6. https://doi.org/10.1097/00005110200104000-00010.

36. Han SS, Sohn IS, Kim NE. New nurse turnover intention and influencing factors. J Korean Acad Nurs. 2009;39(6).

37. Scanlan, Newton J, Meredith P, Poulsen AA. Enhancing retention of occupational therapists working in mental health: Relationships between wellbeing at work and turnover intention. Aust Occup Ther J. 2013;60(6): 395-403. https://doi.org/10.1111/1440-1630.12074.

38. Griffeth RW, Hom PW, Gaertner HS. A meta-analysis of antecedents and correlates of employee turnover: update, moderator tests, and research implications for the next millennium. J Manag. 2000;3:463-88. https://doi. org/10.1177/014920630002600305. 
39. Alsaraireh F, Griffin MTQ, Ziehm SR, Fitzpatrick JJ. Job satisfaction and turnover intention among Jordanian nurses in psychiatric units. Int J Ment Health Nurs. 2014;23:460-46. https://doi.org/10.1111/inm.12070.

40. Deng WJ, Xia OD. Problems and countermeasures of children's medical and health service system in China. Health Econ Res. 2018;12:29-31.

41. Yuan JW. A comparative study on the calculation methods of sample size. Statistics and Decision (China). 2013 (1).

42. Tyler D, Steve MR. Assessing the relationship between competence and job role and identity among direct service counseling psychologists. J Psychoeduc Assess. 1998;16:135-52. https://doi.org/10.1177/ 073428299801600203

43. Cai CJ. Discussion on the role fuzzy and professional identity of preschool teachers' professional roles. Proceedings of the Academic Research and Creation Achievements of the 92nd Annual Academic Year of the School of Humanities and Social Sciences, Chaoyang University of Science and Technology. 2004: 355-380.

44. Weiss D, Dawis R, England G, Lofquist L. Manual for the Minnesota satisfaction questionnaire. Minneapolis: University of Minnesota Press of Industrial Relations Center; 1967.

45. Helena M. Minnesota satisfaction questionnaire - psychometric properties and validation in a population of Portuguese Hospital Workers. M.D. Thesis, University of Porto, Porto, Portugal 2012. https://doi.org/10.26537/iirh.v0i3.1825.

46. Troy LU. A study of the job satisfaction of Nebrsk School Superintendents. Ph.D. Thesis, University of Nebraska, Nebraska 2012.

47. Jing LF, Anne ST, Katherine $X$, et al. The influence of relational demography and Guanxi: the Chinese case. Organ Sci. 1998;9:471-88. https://doi.org/10. 1287/orsc.9.4.471.

48. Zhang M, Zhang $\mathrm{P}, \mathrm{Xu}$ C. Turnover intention of outpatient nurses in Class III Grade I hospitals and its influence factors. J Nurs. 2014;21:21-4.

49. Podsakoff, Philip M, et al. Common method biases in behavioral research a critical review of the literature and recommended remedies. J Appl Psychol. 2003;88:879-930. https://doi.org/10.1037/0021-9010.88.5.879.

50. Xu W, Zhang SC. Chinese Paediatricians face a crisis: should they stay or leave? Pediatrics. 2014;134:1045-7. https://doi.org/10.1542/peds.2014-1377.

51. Wang WX, Fan M, Lu ZX. Study on the inpatient doctor allocation standard of the tertiary general hospitals. Chinese Health Econ. 2010;29(12):54-6.

52. Rosta J, Nylenna M, Aasland OG. Job satisfaction among hospital doctors in Norway and Germany. A comparative study on national samples. Scand J Public Health. 2009;37:503-8. https://doi.org/10.1177/1403494809106504.

53. Tong W, Yan Z, Xue W, Guo T. Factors influencing turnover intention among primary care doctors: a cross-sectional study in Chongqing, China. Hum Resour Health. 2018;16:10. https://doi.org/10.1186/s12960-018-0274-z.

54. Ali Jadoo SA, Aljunid SM, Dastan I, Tawfeeq RS, Mustafa MA, Ganasegeran K, et al. Job satisfaction and turnover intention among Iraqi doctors-a descriptive cross-sectional multicentre study. Hum Resour Health. 2015;13: 21. https://doi.org/10.1186/s12960-015-0014-6.

55. National Bureau of Statistics of China. National data. http://data.stats.gov.cn/ easyquery.htm? $\mathrm{cn}=\mathrm{C} 01 \& z \mathrm{z}=\mathrm{A0}$ A0E\&sj=2018 (Assessed 11 Jun 2019).

56. Sun J, Ma J, Hu G, et al. Welfare, wellness, and job satisfaction of Chinese physicians: a national survey of public tertiary hospitals in China. Int J Health Plann Mgmt. 2017;32:270-84. https://doi.org/10.1002/hpm.2420.

57. Chen CJ, Chen L. Reasons and countermeasures for shortage of paediatricians in China. J Med Theor Prac. 2017;30:2181-3.

58. Yan N, Yang Y-J, Yang X-X. Relationship between job stress and turnover intention based of professional identity in nurses. Chinese Hosp Manage. 2018;38:73-5 10.01-5329(2018)07-0073-03.

\section{Publisher's Note}

Springer Nature remains neutral with regard to jurisdictional claims in published maps and institutional affiliations.

\section{Ready to submit your research? Choose BMC and benefit from:}

- fast, convenient online submission

- thorough peer review by experienced researchers in your field

- rapid publication on acceptance

- support for research data, including large and complex data types

- gold Open Access which fosters wider collaboration and increased citations

- maximum visibility for your research: over $100 \mathrm{M}$ website views per year

At BMC, research is always in progress.

Learn more biomedcentral.com/submissions 